\title{
Analysis on Awareness of Functional Dyspepsia and Rome Criteria Among Japanese Internists by the Self-administered Questionnaires
}

\author{
Hiroshi Kaneko ${ }^{1 *}$ and Hirohito Tsuboi ${ }^{2}$ \\ ${ }^{1}$ Department of Internal Medicine, Hoshigaoka Maternity Hospital, Chikusa, Nagoya, Aichi, Japan; and ${ }^{2}$ Department of Drug Management and \\ Policy, Institute of Medical, Pharmaceutical \& Health Sciences, Kanazawa University, Kakuma-machi, Kanazawa, Ishikawa, Japan
}

\begin{abstract}
Background/Aims
Functional dyspepsia (FD) is one of the commonest diseases in the field of Internal Medicine. The Japanese Society of Gastroenterology (JSGE) has been enlightening the term and concept of FD. Aim of this survey was to elucidate the understanding status of FD and Rome criteria and attitude toward FD among Japanese internists.
\end{abstract}

\section{Methods}

Data were collected at the time of lifelong education course for certified members of Japanese Society of Internal Medicine. Self-administered questionnaires were delivered to the medical doctors prior to the lectures.

\section{Results}

Analysis subjects were 1,623 (24-90 years old) internists among 1,660 medical doctors out of 4,264 attendees. The terms related to FD were known in 62.0-68.9\% of internists, whereas $95.5 \%$ understood chronic gastritis. Internists who had been taking care of FD patients informed them as chronic gastritis (50.0\%), FD in Japanese Kanji character (50.8\%) and FD in Kanji and Katakana (18.6\%). Logistic linear regression analysis revealed that positive factors for the understanding of FD and intensive care for FD patients were practitioner, caring many patients and certified physician by JSGE. Existence of Rome criteria was known in $39.9 \%$ of internists, and $31.8 \%$ out of them put it to practical use. The certified physician by JSGE was a positive factor for awareness, but not for utilization.

\section{Conclusions}

The results suggest the needs of enlightening the medical term FD in Japan and revision of Rome criteria for routine clinical practice. Precise recognition of FD may enhance efficient patient-based clinical practice.

(J Neurogastroenterol Motil 2014;20:94-103)

\section{Key Words}

Attitude; Awareness; Functional dyspepsia; Japan; Rome criteria

Received: September 6, 2013 Revised: October 6, 2013 Accepted: October 23, 2013

(c) This is an Open Access article distributed under the terms of the Creative Commons Attribution Non-Commercial License (http://creativecommons. org/licenses/by-nc/3.0) which permits unrestricted non-commercial use, distribution, and reproduction in any medium, provided the original work is properly cited.

*Correspondence: Hiroshi Kaneko, MD, PhD

Department of Internal Medicine, Hoshigaoka Maternity Hospital 27 Inoue, Chikusa, Nagoya, Aichi 464-0026, Japan

Tel: +81-52-782-6211, Fax: +81-52-782-2678, E-mail: hkaneko@fujita-hu.ac.jp

Financial support: None.

Conflicts of interest: None.

Author contributions: Hiroshi Kaneko designed and performed this survey; Hirohito Tsuboi analyzed the data; Hiroshi Kaneko and Hirohito Tsuboi wrote the paper. 


\section{Introduction}

Approximately $10 \%$ to $40 \%$ of general populations report chronic or recurrent dyspeptic symptoms such as epigastric pain and discomfort. ${ }^{1,2}$ It is estimated that approximately one out of two people seeks health care for their dyspepsia at some time in their life. ${ }^{1,3}$ Functional dyspepsia (FD) is defined as the presence of one or more dyspepsia symptoms that are considered to originate from the gastroduodenal regions, in the absence of any organic, systematic, or metabolic disease that is likely to be responsible for the symptoms. ${ }^{4}$ About $45 \%$ to $65 \%$ of the patients suffering from chronic or recurrent dyspeptic symptoms have been diagnosed as $\mathrm{FD}^{5,6}$ and $\mathrm{FD}$ is one of the commonest diseases in the field of Internal Medicine.

In terms of terminology related to $\mathrm{FD}$, one of the crucial problems underlying FD care in medical facilities under the regulation of Japanese medical insurance system had been an absence of suitable and acceptable translation of "dyspepsia" into Japanese. The Japanese Society of Gastroenterology (JSGE) has been enlightening the term and concept of FD for last several years in accordance with the worldwide spread of enlightenment on functional gastrointestinal disorders (FGID) by Rome committee (Rome criteria). ${ }^{7}$ The JSGE has recommended the diagnostic term as "functional dyspepsia" by the combination of Japanese Kanji characters and Katakana letters, although almost all the diagnostic terms in Japanese have been expressed by Kanji. In Japan, acotiamide ${ }^{8}$ has been just launched in June, 2013 for FD described by Kanji and Katakana letters for the first time. Physicians did not record FD as a diagnosis in the medical record before the release of acotiamide, although much knowledge of FD has been present. However, understanding the medical terms related to FD has not been reported.

From another viewpoint, it has been pointed out that dyspepsia is not a term usually understood by patients. ${ }^{9}$ In terms of drug therapy for FD, acid-suppressive and prokinetic drugs have been effective for dyspepsia, ${ }^{10}$ although high-quality studies investigating the true utility of these agents applicable for FD in a randomized and blinded fashion are still lacking. ${ }^{11}$ As it has been reported that the quality of life of FD patients is impaired, ${ }^{7,12}$ and that employees with FD have greater costs at all places of service and lower productivity than employees without FD, ${ }^{13,14}$ general physicians as well as gastroenterologists have to care for them intensively. However, there have been no massive analyses on explanation, prescription and motivation for FD.
Among many definitions and criteria of FGID, Rome criteria have been mostly utilized especially in clinical trials in the world. Lea et $\mathrm{al}^{15}$ reported that only less than a quarter of general practitioners (GPs) knew Rome criteria for IBS and that $4 \%$ of them used it in UK. Data on awareness and utilization of Rome criteria for FD have not been reported.

The aim of this survey was to elucidate understanding status of FD among Japanese internists. In addition, an attitude (explanation, medication and motivation) toward FD patients and recognition of Rome criteria were investigated.

\section{Materials and Methods}

\section{Participants}

This study was conducted on attendees at lifelong education courses for certified members of the Japanese Society of Internal Medicine (JSIM). The educational programs were held in 3 cities (Tokyo, Osaka and Sendai) of Japan in 2009, and 4,264 physicians attended. Data were obtained from self-administered questionnaires concerning persistent dyspeptic symptom(s) located in the epigastrium without definite or possible organic disease (functional dyspepsia like [FD-L]). The questionnaires were distributed to the attendances prior to the lectures, and 1,660 attendees aged 24 to 90 years old (38.9\%) agreed to participate in the present study. This protocol was approved by the JSIM. A submission was optional and unregistered, and it did not affect the credit of the education course. This ethical information was written clearly in the instruction of the questionnaire.

\section{Measures}

The questionnaire contains demographic information including age (10-year interval), gender, specialty (Internal Medicine, Surgery, Psychiatry and Pediatrics etc.), specific field (Gastroenterology/other fields of Medicine: Cardiology, Endocrinology, Hematology and Neurology etc/General Medicine), periods of clinical experience (less or equal to 5 years/ 6 to 10 years/11 to 20 years/21 to 30 years/31 to 40 years/more than 40 years), working form (practitioner/hospital doctor/others), working area judged by submitter (urban/suburban/rural), certified doctor by JSIM (yes/no) and certified specialist by the JSGE (yes/no). It was also assessed: understandings of the medical terms listed below (more than one was permitted), monthly care number of FD-L patients, the way to inform the FD-L symptoms to patients, medication, 
attitudes towards the FD-L patients, and knowledge and application of the Rome criteria.

Medical terms considered included FD in English, FD by Japanese Kanji, FD by Kanji and Katakana and non-ulcer dyspepsia (NUD) in English; other medical terms listed in Kanji characters which have been officially and clinically utilized in gastrointestinal tract diseases were irritable bowel syndrome (IBS), chronic gastritis, reflux esophagitis and non-erosive reflux disease (NERD).

\section{Statistical Methods}

Data were analyzed using the IBM SPSS Statistics software (Japanese version 19; IBM SPSS, Tokyo, Japan). Chi-square test was utilized for comparison of knowledge on medical terminology according by each factors. Binary logistic regression model was applied to calculate odds ratios (OR) and 95\% confidence intervals $(\mathrm{CI})$ for assessing variables related with the knowledge of medical terms expressing FD-L, related variables with physicians' attitude towards caring for FD-L patients, and related variables with knowledge and application of the Rome criteria. A probability $P$-value less than 0.05 was considered significant.

\section{Results}

Nineteen participants with missing values concerning FD-L questions, 8 who were working outside of the Internal Medicine, and 10 whose working fields were uncertain were excluded prior to analysis; consequently, 1,623 subjects were analyzed. Table 1 presents characteristics of analyzed participants. Almost all of the responders (96.0\%) were the certified doctor by the JSIM. Participants ( $n=1,623)$ knew the term "reflux esophagitis" the most (97.5\%), followed by "IBS" (95.6\%), "chronic gastritis" (95.5\%), FD (68.9\%), "FD by Japanese Kanji" (66.9\%), "FD by Japanese Kanji and Katakana" (62.0\%), NUD (61.6\%), and “NERD” (58.7\%) (Table 1).

Difference in knowledge of each medical term from the viewpoint of variables was analyzed by chi-square tests (data not shown). FD, "FD by Kanji," "FD by Kanji and Katakana," "NUD" and "NERD" were significantly highly recognized among physicians with specific field of Gastroenterology, certified specialist by the JSGE, working as a practitioner, and caring for many patients. FD, "FD by Kanji and Katakana," and NUD, but not "FD by Kanji," were more recognized in doctors with clinical experience duration of 11 to 40 years compared to those of either less than 11 or more than 40 years. "Chronic gastritis,"
Table 1. Descriptive Data Obtained From Participated Internists and Knowledge Rate of the Term "Functional Dyspepsia-like" ( $\mathrm{N}=1,623)$

\begin{tabular}{|c|c|c|}
\hline \multicolumn{2}{|c|}{ Variable } & \multirow{2}{*}{$\begin{array}{c}\mathrm{n}(\%) \\
835(51.4)\end{array}$} \\
\hline Place at which obtain & Tokyo & \\
\hline questionaire information & Osaka & $535(33.0)$ \\
\hline$(\mathrm{n}=1,623)$ & Sendai & $253(15.6)$ \\
\hline \multirow[t]{2}{*}{ Gender $(\mathrm{n}=1,531)$} & Men & $1,221(75.2)$ \\
\hline & Women & $310(19.1)$ \\
\hline \multirow[t]{8}{*}{ Age $(n=1,621)$} & $20 \mathrm{~s}$ & $11(0.7)$ \\
\hline & $30 \mathrm{~s}$ & $194(12.0)$ \\
\hline & $40 \mathrm{~s}$ & $496(30.6)$ \\
\hline & $50 \mathrm{~s}$ & $509(31.4)$ \\
\hline & $60 \mathrm{~s}$ & $241(14.9)$ \\
\hline & $70 \mathrm{~s}$ & $137(8.5)$ \\
\hline & $80 \mathrm{~s}$ & $32(2.0)$ \\
\hline & $90 \mathrm{~s}$ & $1(0.1)$ \\
\hline \multirow{7}{*}{$\begin{array}{l}\text { Years of clinical } \\
\text { experience } \\
(\mathrm{n}=1,558[\mathrm{yr}])\end{array}$} & $\leq 5$ & $23(1.4)$ \\
\hline & $6-10$ & $112(7.1)$ \\
\hline & $11-15$ & $182(11.5)$ \\
\hline & $16-20$ & $235(14.8)$ \\
\hline & $21-30$ & $601(37.8)$ \\
\hline & $31-40$ & $283(17.8)$ \\
\hline & $\geq 41$ & $152(9.6)$ \\
\hline \multirow[t]{3}{*}{ Specific field $(n=1,623)$} & General internal medicine & $472(29.1)$ \\
\hline & Gastroenterology & $408(25.1)$ \\
\hline & Others & $743(45.8)$ \\
\hline \multirow{3}{*}{$\begin{array}{l}\text { Working form } \\
(\mathrm{n}=1,582)\end{array}$} & Practitioner & $709(43.7)$ \\
\hline & Hospital doctor & $806(49.7)$ \\
\hline & Others $^{\mathrm{a}}$ & $67(4.1)$ \\
\hline \multirow{2}{*}{$\begin{array}{l}\text { Certified doctor by } \\
\text { the Japanese Society of } \\
\text { Internal Medicine } \\
(n=1,623)\end{array}$} & Certified & $1,558(96.0)$ \\
\hline & Uncertified & $65(4.0)$ \\
\hline \multirow{2}{*}{$\begin{array}{l}\text { Certified specialist by } \\
\text { the Japanese Society of } \\
\text { Gastroenterology } \\
(n=1,622)\end{array}$} & Certified & $408(25.2)$ \\
\hline & Uncertified & $1,214(74.8)$ \\
\hline \multirow{3}{*}{$\begin{array}{l}\text { Working area } \\
(\mathrm{n}=1,402)\end{array}$} & Urban & $897(54.7)$ \\
\hline & Suburban & $342(20.8)$ \\
\hline & Rural & $402(24.5)$ \\
\hline \multirow{2}{*}{$\begin{array}{l}\text { Do you care FD-L } \\
\text { patients? }(\mathrm{n}=1,623)\end{array}$} & Yes & $1,372(84.5)$ \\
\hline & No & $251(15.5)$ \\
\hline \multirow{8}{*}{$\begin{array}{l}\text { Do you know the } \\
\text { following medical term? } \\
(\mathrm{n}=1,623)^{\mathrm{b}}\end{array}$} & Functional dyspepsia (FD) & $1,119(68.9)$ \\
\hline & FD by Japanese Kanji & $1,086(66.9)$ \\
\hline & $\begin{array}{l}\text { FD by Japanese Kanji and } \\
\text { Katakana }\end{array}$ & $1,006(62.0)$ \\
\hline & NUD (non-ulcer dyspepsia) & $1,000(61.6)$ \\
\hline & Chronic gastritis & $1,550(95.5)$ \\
\hline & Irritable bowel syndrome & $1,552(95.6)$ \\
\hline & Reflux esophagitis & $1,582(97.5)$ \\
\hline & Non-erorive reflux disease & $952(58.7)$ \\
\hline
\end{tabular}

${ }^{\mathrm{a}}$ Including research, industrial medicine, nursing home and part-time etc., ${ }^{\mathrm{b}}$ More than one answer was permitted.

FD, functional dyspepsia; FD-L, functional dyspepsia-like (means persistent dyspeptic symptom located in the epigastrium without definite or possible organic disease). 


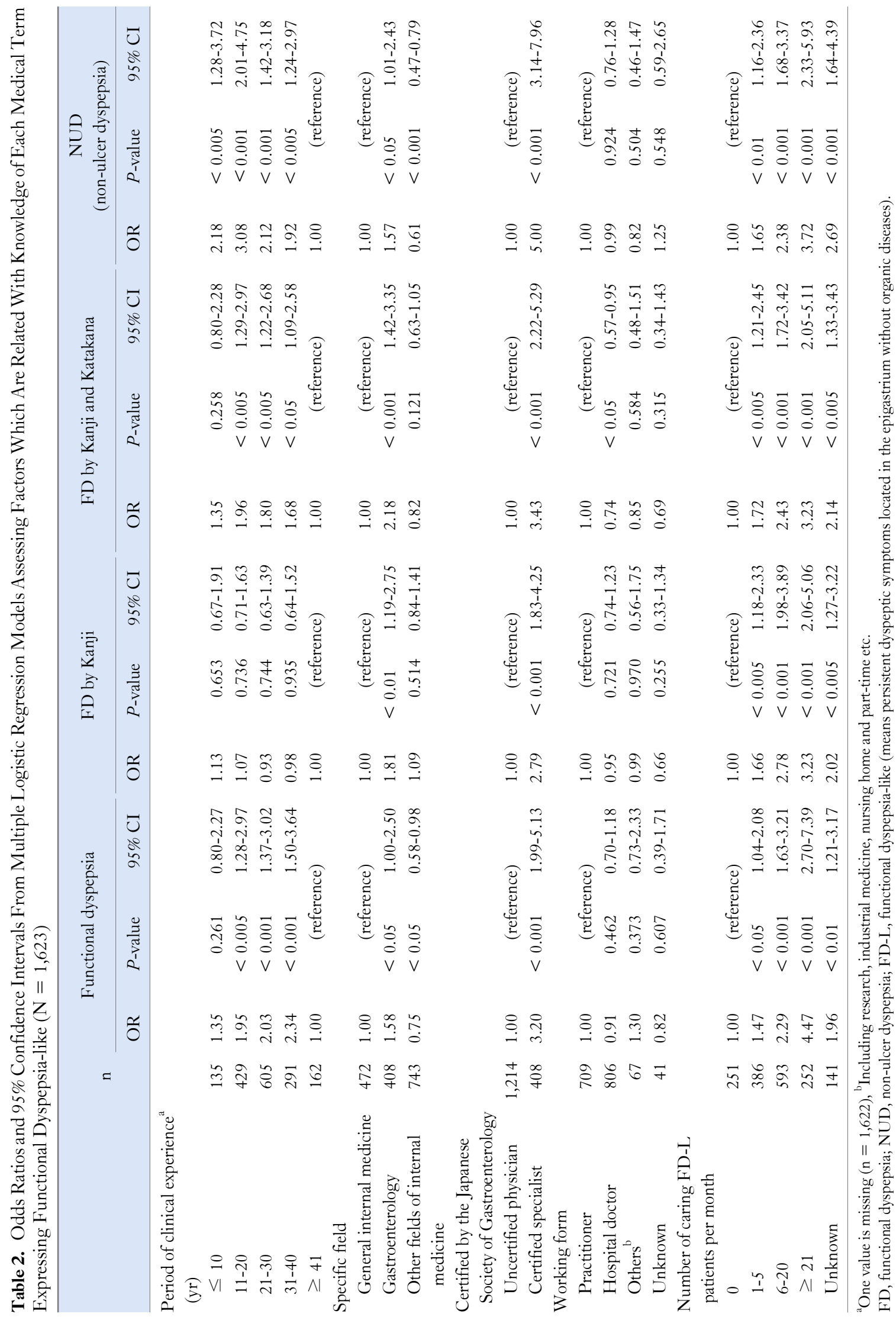


"IBS" and "reflux esophagitis" were highly known in regardless of period of clinical experience, working form and number of caring FD-L patients per month.

Next, logistic regression analysis was applied to find out variables that can be related with the understanding of terms expressing FD-L. Table 2 reveals OR and 95\% CI of independent variables to explain each term of FD-L. The internists who had been caring more number of FD-L patients per month significantly understood more all of the 4 terms (FD, "FD by Kanji," "FD by Kanji and Katakana" and NUD) in comparison with those who did not. Subjects who were engaged in gastroenterology, and certified internists by the JSGE knew all 4 terms concerning FD more significantly in comparison with the references. Internists with 11-40 years of clinical experiences knew FD and "FD by kanji and katakana" significantly more in comparison with those with more than 41 years of clinical experiences, and internists with less than 40 years of clinical experiences knew NUD more in comparison with those with more than 41 years of clinical experiences, whereas there were no significant differences in "FD by kanji” according to period of clinical experiences.

Out of 1,623 doctors, 1,372 had been caring for FD-L patients (84.5\%). Among the 1,372 physicians, 697 (50.8\%) used "FD by Japanese Kanji" for informing FD-L patients, and 686 (50.0\%) utilized "chronic gastritis" (Table 3). Explanation of "FD by Japanese Kanji and Katakana" and "no worry" was $18.6 \%$ and $12.0 \%$, respectively. Prokinetic agent (79.4\%) and gastric acid secretion inhibitor $(66.3 \%)$ were frequently prescribed. Anxiolytics (25.1\%) and antidepressants (12.2\%) were also used (Table 3 ). In terms of the care attitude, $72.6 \%$ of physicians generally cared for the FD-L patients in daily practice. And $23.6 \%$ enthusiastically (intensively) took care of the patients. In reference to the Rome criteria, 547 out of 1,372 physicians with caring FD-L patients $(39.9 \%)$ knew the criteria, and 174 out of $547(31.8 \%)$ applied it to patient care (Table 3).

Variables affecting physicians' attitudes in caring for FD-L patients were also analyzed. Table 4 displays OR and 95\% CI analyzed by multiple logistic regression: examining FD-L patients enthusiastically $(\mathrm{n}=296)$ vs. others $(\mathrm{n}=1,075$ : including generally and unwillingly; Table 3). Female internists in comparison with male, certified internists by the JSIM in comparison with uncertified, period of clinical experience longer than 31 years in comparison with less than 10 years, and hospital doctors in comparison with practitioners cared for FD-L patients less enthusiastically significantly. On the other hand, certified physicians by the JSGE in comparison with uncertified, and physicians who cared
Table 3. Explanation, Medication and Attitude to Functional Dyspepsia-like Patients

\begin{tabular}{|c|c|}
\hline Questions & $\mathrm{n}(\%)$ \\
\hline \multicolumn{2}{|l|}{$\begin{array}{l}\text { How many care FD-L patients per month? } \\
(\mathrm{n}=1,372)\end{array}$} \\
\hline $1-5$ & $386(28.1)$ \\
\hline $6-20$ & $593(43.2)$ \\
\hline$\geq 21$ & $252(18.4)$ \\
\hline Patients number unknown & $141(10.3)$ \\
\hline \multicolumn{2}{|l|}{$\begin{array}{l}\text { What kind of terms do you use to inform FD-L } \\
\text { patients? }(\mathrm{n}=1,372)^{\mathrm{a}}\end{array}$} \\
\hline Functional dyspepsia & $366(26.7)$ \\
\hline FD by Japanese Kanji & $697(50.8)$ \\
\hline FD by Japanese Kanji and Katakana & $255(18.6)$ \\
\hline NUD (non-ulcer dyspepsia) & $261(19.0)$ \\
\hline Chronic gastritis & $686(50.0)$ \\
\hline No abnormalities & $84(6.1)$ \\
\hline No worry & $165(12.0)$ \\
\hline Just imagination & $10(0.7)$ \\
\hline Inform nothing & $6(0.4)$ \\
\hline Others & $50(3.6)$ \\
\hline \multicolumn{2}{|l|}{$\begin{array}{l}\text { What kind of medicine do you prescribe for FD-L } \\
\text { patients? }(\mathrm{n}=1,372)^{\mathrm{a}}\end{array}$} \\
\hline Gastric acid secretion inhibitor & $909(66.3)$ \\
\hline Prokinetic agent & $1,090(79.4)$ \\
\hline Mucosal protecting agent & $615(44.8)$ \\
\hline Antiemetic & $173(12.6)$ \\
\hline Herbal medicine & $307(22.4)$ \\
\hline Anxiolytic drug & $345(25.1)$ \\
\hline Antidepressant & $168(12.2)$ \\
\hline No prescription & $32(2.3)$ \\
\hline Others & $28(2.0)$ \\
\hline \multicolumn{2}{|l|}{ How do you care FD-L patients? $(\mathrm{n}=1,372)$} \\
\hline Enthusiastically & $296(23.6)$ \\
\hline Generally & $913(72.6)$ \\
\hline Unwillingly & $48(3.8)$ \\
\hline Consult to specialist & $95(7.2)$ \\
\hline Others & $13(1.0)$ \\
\hline \multicolumn{2}{|l|}{ Do you know the Rome criteria? } \\
\hline Out of 1,623 responders & $587(36.2)$ \\
\hline Out of 1,372 responders with FD-L patients' care & $547(39.9)$ \\
\hline $\begin{array}{l}\text { Do you apply the Rome criteria to your patient care? } \\
(\mathrm{n}=547)^{\mathrm{b}}\end{array}$ & $174(31.8)$ \\
\hline
\end{tabular}

${ }^{a}$ More than one answer was permitted, ${ }^{\mathrm{b}} 547$ participants who knew the Rome criteria out of 1,372 responders with functional dyspepsia-like patients' care are presented.

FD, functional dyspepsia; NUD, non-ulcer dyspepsia; FD-L, functional dyspepsia-like (means persistent dyspeptic symptoms located in the epigastrium without organic diseases).

more than 6 FD-L patients per month in comparison with those less than 5 per month cared for FD-L patients more enthusiastically. 
Table 4. Odds Ratios and 95\% Confidence Intervals From Multiple Logistic Regression Models Assessing Which Factors Are Associated With Physician's Enthusiastic Care for Functional Dyspepsia-like Patients (Enthusiastic: $\mathrm{n}=296$ vs. Others: $\mathrm{n}=1,075$ )

\begin{tabular}{|c|c|c|c|c|}
\hline & $\mathrm{n}(\%)$ & OR & $P$-value & $95 \% \mathrm{CI}$ \\
\hline \multicolumn{5}{|l|}{ Gender } \\
\hline Men & $1,056(77.0)$ & 1.00 & \multicolumn{2}{|c|}{ (reference) } \\
\hline Women & $237(17.3)$ & 0.61 & $<0.05$ & $0.40-0.94$ \\
\hline Unknown & $78(5.7)$ & 0.98 & 0.963 & $0.55-1.77$ \\
\hline \multicolumn{5}{|l|}{ Period of clinical experience (yr) } \\
\hline$\leq 10$ & $87(6.3)$ & 1.00 & \multicolumn{2}{|c|}{ (reference) } \\
\hline $11-20$ & $357(26.0)$ & 0.59 & 0.097 & $0.32-1.10$ \\
\hline $21-30$ & $534(38.9)$ & 0.56 & 0.060 & $0.30-1.01$ \\
\hline $31-40$ & $262(19.1)$ & 0.52 & $<0.05$ & $0.27-0.99$ \\
\hline$\geq 41$ & $131(9.6)$ & 0.48 & $<0.05$ & $0.23-0.99$ \\
\hline \multicolumn{5}{|l|}{ Specific field } \\
\hline General internal medicine & $421(30.7)$ & 1.00 & \multicolumn{2}{|c|}{ (reference) } \\
\hline Gastroenterology & $387(28.2)$ & 1.30 & 0.221 & $0.86-1.97$ \\
\hline $\begin{array}{l}\text { Other fields of internal } \\
\text { medicine }\end{array}$ & $563(41.1)$ & 0.74 & 0.109 & $0.51-1.07$ \\
\hline \multicolumn{5}{|l|}{ Certified by the Japanese } \\
\hline \multicolumn{5}{|l|}{ Society of Gastroenterology ${ }^{a}$} \\
\hline Uncertified physician & $992(72.4)$ & 1.00 & \multicolumn{2}{|c|}{ (reference) } \\
\hline Certified specialist & $379(27.6)$ & 2.30 & $<0.001$ & $1.51-3.50$ \\
\hline \multicolumn{5}{|l|}{ Working form } \\
\hline Practitioner & $672(49.0)$ & 1.00 & \multicolumn{2}{|c|}{ (reference) } \\
\hline Hospital doctor & $630(46.0)$ & 0.65 & $<0.01$ & $0.48-0.89$ \\
\hline Others $^{\mathrm{b}}$ & $35(2.6)$ & 0.69 & 0.478 & $0.25-1.93$ \\
\hline Unknown & $34(2.5)$ & 0.83 & 0.741 & $0.33-2.08$ \\
\hline \multicolumn{5}{|l|}{$\begin{array}{l}\text { Number of caring FD-L } \\
\text { patients per month }\end{array}$} \\
\hline $1-5$ & $386(28.2)$ & 1.00 & \multicolumn{2}{|c|}{ (reference) } \\
\hline $6-20$ & $593(43.3)$ & 1.52 & $<0.05$ & $1.04-2.24$ \\
\hline$\geq 21$ & $251(18.3)$ & 3.32 & $<0.001$ & $2.16-5.10$ \\
\hline Unknown & $141(10.3)$ & 1.39 & 0.231 & $0.81-2.40$ \\
\hline
\end{tabular}

${ }^{a}$ One value is missing, and total of 1,371 were analyzed, ${ }^{b}$ Including research, industrial medicine, nursing home and part-time etc.

FD-L, functional dyspepsia-like (means persistent dyspeptic symptoms located in the epigastrium without organic diseases).

We analyzed 1,372 participants who cared for FD-L patients out of 1,623 (see Table 1).

Only 277 out of the 709 practitioners (39\%) knew the Rome criteria, compared to 155 out of 187 hospital specialists (e.g., internists with Gastroenterology subspecialty working at hospital) $(83 \%)($ Chi-square $=114, P<0.00001)$, and 306 out of 408 certified physicians by the JSGE (75\%) (Chi-square $=134, P<$ $0.00001)$. The positive factor for the awareness was certified physicians by the JSGE and the more number of caring FD-L patients per month (Table 5). The negative factor for the application was periods of clinical experience of "21-30" and "more than 40 " years in comparison with the experience with "less or equal to 10 years." The working form did not affect the knowledge of Rome criteria (Table 5).
In 547 participants who understood the Rome criteria, factors that affect application of the criteria to clinical practice were analyzed by a logistic regression model: ORs and 95\% CIs of each variable associated with the application of the Rome criteria are exhibited in Table 6 . The positive factor for the application was the more number of caring FD-L patients per month. The negative factor for the application was periods of clinical experience with "11-20," "21-30" and "31-40" years in comparison with the experience with "less or equal to 10 years." The working form and JSGE certified physician did not affect the utilization of Rome criteria. 
Table 5. Odds Ratios and 95\% Confidence Intervals From Multiple Logistic Regression Models Assessing Which Factors Are Related With Physicians Awarenss on Rome Criteria $(\mathrm{N}=1,621)$

\begin{tabular}{|c|c|c|c|c|}
\hline & $\mathrm{n}$ & OR & $P$-value & $95 \% \mathrm{CI}$ \\
\hline \multicolumn{5}{|c|}{ Period of clinical experience (yr) } \\
\hline$\leq 10$ & 135 & 1.00 & \multicolumn{2}{|c|}{ (reference) } \\
\hline $11-20$ & 429 & 0.75 & 0.220 & $0.47-1.19$ \\
\hline $21-30$ & 604 & 0.55 & $<0.05$ & $0.35-0.88$ \\
\hline $31-40$ & 291 & 0.65 & 0.093 & $0.40-1.07$ \\
\hline$\geq 41$ & 162 & 0.56 & $<0.05$ & $0.32-0.98$ \\
\hline \multicolumn{5}{|l|}{ Working form } \\
\hline Practitioner & 708 & 1.00 & \multicolumn{2}{|c|}{ (reference) } \\
\hline Hospital doctor & 805 & 1.02 & 0.856 & $0.79-1.33$ \\
\hline Others $^{\mathrm{a}}$ & 67 & 1.08 & 0.819 & $0.56-2.08$ \\
\hline Unknown & 41 & 0.81 & 0.605 & $0.37-1.79$ \\
\hline \multicolumn{5}{|c|}{ Number of caring FD-L patients per month } \\
\hline 0 & 250 & 1.00 & \multicolumn{2}{|c|}{ (reference) } \\
\hline $1-5$ & 386 & 2.28 & $<0.001$ & $1.49-3.55$ \\
\hline $6-20$ & 593 & 3.16 & $<0.001$ & $2.07-4.81$ \\
\hline$\geq 21$ & 251 & 5.02 & $<0.001$ & $3.07-8.23$ \\
\hline Unknown & 141 & 2.37 & $<0.005$ & $1.38-4.08$ \\
\hline \multicolumn{5}{|c|}{ Certified by the Japanese Society of Gastroenterology } \\
\hline Uncertified physician & 1,213 & 1.00 & \multicolumn{2}{|c|}{ (reference) } \\
\hline Certified specialist & 408 & 8.99 & $<0.001$ & $6.85-11.8$ \\
\hline
\end{tabular}

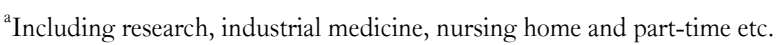

FD-L, functional dyspepsia-like (means persistent dyspeptic symptoms located in the epigastrium without organic diseases).

As 2 data are missing in "Knowledge of Rome criteria," remained 1,621 were analyzed. Selected independent variables except for working form were significantly related with knowledge of Rome criteria by univariate regression analysis.

\section{Discussion}

Physicians have been labeling "chronic gastritis" in patients with gastric mucosal inflammation that is confirmed by histological or endoscopic findings and/or persistent dyspeptic symptom(s) in the absence of organic diseases such as peptic ulcer. In practice, a diagnosis of chronic gastritis in Japan is primarily based on upper abdominal symptoms without performing an endoscopic examination especially among primary care physicians. ${ }^{16}$ Additionally, FD had not been listed under Japanese medical insurance system until June, 2013. In fact, prokinetic drugs including mosapride and itopride have been prescribed with an indication of chronic gastritis-related dyspeptic symptom(s) in Japan. Therefore, it seemed reasonable that the percentage of knowing FD and FD-related terms was lower than that of chronic gastritis in the present study. As this study was performed in 2009, the present recognition rate of FD might be higher due to the recent launch of acotiamide for $\mathrm{FD},{ }^{8}$ but not for chronic gastritis, for the first time in 2013. However, knowledge of NERD was $58.7 \%$, which was lower than that of $\mathrm{FD}$, although a certain proton pump inhibitor, which has been prescribed in patients with peptic ulcer and reflux esophagitis, was already approved as additional application for NERD in 2006. Therefore, it is unlikely that the relatively low percentage of recognition of the term FD demonstrated in the present study solely depended on the lack of FD as medically permitted record and on the 3-year interval of the research.

The present findings that chronic gastritis, IBS and reflux esophagitis were highly known in regardless of working form and number of caring FD-L patients per month, and that FD, FD by Kanji, FD by Kanji and Katakana, NUD and NERD were significantly highly recognized among physicians working as a practitioner, and caring many patients suggest that FD and FD-related terms were well recognized among practitioners caring for more FD-L patients. This was proved by the analysis of the present study (data not shown). The logistic regression analysis revealed that recognition of FD by Kanji did not differ in terms of period of clinical experience and working form in contrast to that of FD by Kanji and Katakana (Table 2). The discrepancy may re- 
Table 6. Odds Ratios and 95\% Confidence Intervals From Multiple Logistic Regression Models Assessing Which Factors Are Related With Physicians Applying Rome Criteria to Clinical Care ( $\mathrm{N}=524)$

\begin{tabular}{|c|c|c|c|c|}
\hline & $\mathrm{n}$ & OR & $P$-value & $95 \% \mathrm{CI}$ \\
\hline \multicolumn{5}{|c|}{ Period of clinical experience (yr) } \\
\hline$\leq 10$ & 35 & 1.00 & \multicolumn{2}{|c|}{ (reference) } \\
\hline $11-20$ & 144 & 0.42 & $<0.05$ & $0.19-0.91$ \\
\hline $21-30$ & 207 & 0.28 & $<0.05$ & $0.13-0.61$ \\
\hline $31-40$ & 100 & 0.38 & $<0.05$ & $0.17-0.86$ \\
\hline$\geq 41$ & 38 & 0.52 & 0.180 & $0.20-1.37$ \\
\hline \multicolumn{5}{|l|}{ Working form } \\
\hline Practitioner & 261 & 1.00 & \multicolumn{2}{|c|}{ (reference) } \\
\hline Hospital doctor & 242 & 0.92 & 0.683 & $0.61-1.39$ \\
\hline Others $^{\mathrm{a}}$ & 12 & 1.04 & 0.852 & $0.28-3.84$ \\
\hline Unknown & 9 & 2.56 & 0.182 & $0.64-10.2$ \\
\hline \multicolumn{5}{|c|}{ Number of caring FD-L patients per month } \\
\hline $1-5$ & 107 & 1.00 & \multicolumn{2}{|c|}{ (reference) } \\
\hline $6-20$ & 235 & 2.50 & $<0.005$ & $1.39-4.50$ \\
\hline$\geq 21$ & 137 & 3.72 & $<0.001$ & $1.97-7.02$ \\
\hline Unknown & 45 & 3.18 & $<0.005$ & $1.43-7.05$ \\
\hline \multicolumn{5}{|c|}{ Certified by the Japanese Society of Gastroenterology } \\
\hline Uncertified physician & 247 & 1.00 & \multicolumn{2}{|c|}{ (reference) } \\
\hline Certified specialist & 277 & 1.44 & 0.073 & $0.97-2.13$ \\
\hline
\end{tabular}

${ }^{a}$ Including research, industrial medicine, nursing home and part-time etc.

FD-L, functional dyspepsia-like (means persistent dyspeptic symptoms located in the epigastrium without organic diseases).

The number of analyzed participants was 547, which was selected from 1,372 physicians caring for FD-L patients regularly (see Table 3 ). As to 23 data are missing in

"Application of Rome criteria into clinical care" remained 524 were analyzed. Selected independent variables except for working form were significantly related with application of Rome criteria into clinical care by univariate regression analysis.

flect the exceptional usage of Katakana as terms of medical record in Japan.

In terms of explanation to FD-L patients from internists, approximately a half of them used the term FD by Japanese Kanji (50.8\%) and/or chronic gastritis (50.5\%), whereas $18.6 \%$ of the doctors explained patients' disorder as FD by Kanji and Katakana. Bytzer et $\mathrm{al}^{9}$ pointed out that dyspepsia is a not a term usually understood by patients. Kennedy et $\mathrm{al}^{17}$ reported that misperceptions that FD might be risk factors of ulcer and cancer were present among labeled patients as FD. On the other hand, Vakil et $\mathrm{al}^{18}$ demonstrated that terms such as gastritis continue to be used in primary care to describe patients with upper gastrointestinal symptoms in some countries where FD has been utilized in medical practice. Recently, Hongo et $\mathrm{al}^{19}$ clearly demonstrated that among FD-L patients without any specific lesions detected by endoscopy ( $\mathrm{n}=937)$, gastrointestinal symptoms were resolved within one week after the endoscopy in 264 (28.2\%) patients before initiating medication with either mosapride or teprenone, the gastroprotective drugs in Japan. Taken together, detailed explanation of "no visible malignant or pro- gressive abnormality by endoscopy" in addition to "no worry" informed by physicians may be warranted at the initial stage of caring for $\mathrm{FD}$ patients.

The present survey revealed that prokinetic agents and/or gastric acid secretion inhibitors were frequently prescribed at a percentage of $79.4 \%$ and $66.3 \%$, respectively. These results are in the line of recommendation of Rome committee. ${ }^{10}$ Anxiolytics $(25.1 \%)$ and/or antidepressants $(12.2 \%)$ were also prescribed in the present study. These classes of drugs have been demonstrated to be effective for $\mathrm{FD}^{20}$

Of note, positive factors for intensive or enthusiastic care for FD-L patients were certified physicians by the JSGE, practitioner, and more number of caring FD-L in the present study. Dalton et $\mathrm{al}^{21}$ demonstrated that doctors perceived that patients with organic diagnoses had more serious problems, greater disability, and more reasonable requests $(P<0.05$ to $P<0.001)$, compared to those with functional. On the contrary, the patients with functional disorders believed they were more disabled than those with organic disorders $(P<0.05)$. The doctors should recognize this discrepancy of recognition toward FGID. 
In terms of the recognition of Rome criteria, approximately $40 \%$ of internists knew the Rome criteria. Gladman and Gorard ${ }^{22}$ investigated awareness and utilization of Rome criteria for the diagnosis of FGID among 137 GPs and 167 British Society of Gastroenterology members (consultants). Only 16 of 137 GPs (12\%) had heard the Rome criteria, compared to 139 of 167 consultants $(83 \%)(P<0.0001)$. Despite the greater awareness among consultants, 67 consultants $(40 \%)$ reported to use the Rome criteria. Only 4 (3\%) of GPs stated that they used it. ${ }^{22}$ They used the knowledge and utilization of Rome criteria mainly for IBS. Therefore, present study is the first research on awareness of internists of Rome criteria for FD. In the present study, hospital specialists and certified physicians by the JSGE knew more about the Rome criteria compared to practitioners, in agreement with the report by Gladman and Gorard. ${ }^{22}$ However, working form did not affect the knowledge of Rome criteria by multiple logistic regression analysis. Our data suggested that number of caring FD-L patients was crucial in the knowledge of Rome criteria whether the physician was certified or not by the JSGE.

Among the present subjects with knowledge of the Rome criteria $(\mathrm{n}=547), 174(31.8 \%)$ applied the Rome criteria for FD-L patients' care. Of note, the JSGE certified physician was not a factor to affect the utilization of Rome criteria. The reason of the present discrepancy between awareness and application of the Rome criteria among certified physicians by JSGE remains unknown. The criterion for the time from the symptom onset as defined by the Rome III might be responsible, because the patients with dyspepsia usually visit the hospital for evaluation sooner than the 6 months, which is defined as minimum symptom onset time prior to FD diagnosis in the Rome III, in Japan. ${ }^{16,23}$ There were no significant differences in severity of dyspeptic symptoms between the 3 groups (less than 1 month, from 1 to 6 months and more than 6 months). 16,23 Therefore, Manabe et $\mathrm{al}^{23}$ concluded that the 6-month period after onset of dyspeptic symptoms should be shortened at least in the Japanese population experiencing dyspeptic symptoms.

The limitations of the present study include that it is unknown whether the present findings concerning the awareness of terms related to FD and Rome criteria and the attitude toward FD-L patients represent Japanese internists. The subjects were attendees at lifelong education courses for mainly certified member of JSIM, but not recruited randomly from Japanese internists. The percentage of the specific field as Gastroenterology in the present study (25.1\%) was higher than that of the national survey $(17.8 \%)$ released from the Ministry of Health, Labor and
Welfare in 2010 (http://www.mhlw.go.jp/toukei/saikin/hw/ishi/10/ $\mathrm{dl} /$ gaikyo.pdf in Japanese). In addition, although criteria of Rome definition have been changed from I through III, ${ }^{24}$ it cannot be determined as to which version of them was relatively known and utilized under the present setting. The present results are limited to one nation, as available data outside of Japan are lacking.

In conclusion, the results that awareness rate of the terms related to FD was low compared with that of chronic gastritis, whereas the explanation from internists to FD-L patients was FD and chronic gastritis at a similar rate $(50.8 \%$ and $50.0 \%$, respectively) suggest a certain portion of Japanese internists utilized the functional disorder to inform the patients with FD-L. Low rate of explanation term as FD by Japanese Kanji and Katakana and utilization of Rome criteria especially among specialists of Gastroenterology might indicate needs of enlightening the medical term in Japan and revision of Rome criteria for routine clinical practice. Publication of the clinical guideline for FD from the JSGE is scheduled in 2014 and the release of new drug for FD in 2013 may be expected to improve the FD care including terminology with higher motivation to treat FD patients and the position of Rome criteria.

\section{Acknowledgements}

The authors sincerely appreciated professor Soichiro Miura (the principal of National Defense Medical College, Japan) for his kind arrangement of sampling the questionnaires at a lifelong education course for certified members of JSIM.

\section{References}

1. Talley NJ, Zinsmeister AR, Schleck CD, Melton LJ 3rd. Dyspepsia and dyspepsia subgroups: a population-based study. Gastroenterology 1992;102(4 Pt 1):1259-1268.

2. El-Serag HB, Talley NJ. Systemic review: the prevalence and clinical course of functional dyspepsia. Aliment Pharmacol Ther 2004;19:643-654

3. Talley NJ, Boyce P, Jones M. Dyspepsia and health care seeking in a community: How important are psychological factors? Dig Dis Sci 1998;43:1016-1022.

4. Tack J, Talley NJ, Camilleri M, et al. Functional gastroduodenal disorders. Gastroenterology 2006;130:1466-1479.

5. Okumura T, Tanno S, Ohhira M, Tanno S. Prevalence of functional dyspepsia in an outpatient clinic with primary care physicians in Japan. J Gastroenterol 2010;45:187-194.

6. Shaib Y, El-Serag HB. The prevalence and risk factors of functional dyspepsia in a multiethnic population in the United States. Am J Gastroenterol 2004;99:2210-2216.

7. Drossman DA. The functional gastrointestinal disorders and the 
Rome III process. Gastroenterology 2006;130:1377-1390.

8. Matsueda K, Hongo M, Tack J, Saito Y, Kato H. A placebo-controlled trial of acotiamide for meal-related symptoms of functional dyspepsia. Gut 2012;61:821-828.

9. Bytzer P, Talley NJ. Dyspepsia. Ann Intern Med 2001;134(9 Pt 2):815-822.

10. Geeraerts B, Tack J. Functional dyspepsia: past, present, and future. J Gastroenterol 2008;43:251-255.

11. Tack J, Talley NJ. Functional dyspepsia - symptoms, definitions and validity of the Rome III criteria. Nat Rev Gastroenterol Hepatol 2013;10:134-141.

12. Kaji M, Fujiwara Y, Shiba M, et al. Prevalence of overlaps between GERD, FD and IBS and impact on health-related quality of life. J Gastroenterol Hepatol 2010;25:1151-1156.

13. Brook RA, Kleinman NL, Choung RS, Melkonian AK, Smeeding JE, Talley NJ. Functional dyspepsia impacts absenteeism and direct and indirect costs. Clin Gastroenterol Hepatol 2010;8:498-503.

14. Camilleri M, Dubois D, Coulie B, et al. Prevalence and socioeconomic impact of upper gastrointestinal disorders in the United States: results of the US Upper Gastrointestinal Study. Clin Gastroenterol Hepatol 2005;3:543-552.

15. Lea R, Hopkins V, Hastleton J, Houghton LA, Whorwell PJ. Diagnostic criteria for irritable bowel syndrome: utility and applicability in clinical practice. Digestion 2004;70:210-213.

16. Kinoshita Y, Chiba T; FUTURE Study Group. Characteristics of Japanese patients with chronic gastritis: comparison with functional dyspepsia defined by ROME III criteria: based on large-scale sur- vey, FUTURE study. Intern Med 2011;50:2269-2276.

17. Kennedy AT, Weiser KT, Crowell MD, Talley NJ, Lacy BE. Functional dyspepsia: Validation and results of a novel survey instrument to evaluate patient knowledge and perceptions. J Clin Gastroenterol 2009;43:933-940.

18. Vakil N, Malfertheiner P, Salis G, Flook N, Hongo M. An international primary care survey of GERD terminology and guidelines. Dig Dis 2008;26:231-236.

19. Hongo M, Harasawa S, Mine T, et al. Large-scale randomized clinical study on functional dyspepsia treatment with mosapride or teprenone: Japan Mosapride Mega-Study (JMMS). J Gastroenterol Hepatol 2012;27:62-68.

20. Hojo M, Miwa H, Yokoyama T, et al. Treatment of functional dyspepsia with antianxiety or antidepressive agents: systematic review. J Gastroenterol 2005;40:1036-1042.

21. Dalton CB, Drossman DA, Hathaway JM, Bangdiwala SI. Perceptions of physicians and patients with organic and functional gastrointestinal diagnoses. Clin Gastroenterol Hepatol 2004;2:121-126.

22. Gladman LM, Gorard DA. General practitioner and hospital specialist attitudes to functional gastrointestinal disorders. Aliment Pharmacol Ther 2003;17:651-654.

23. Manabe N, Haruma K, Hata J, et al. Clinical characteristics of Japanese dyspeptic patients: is the Rome III classification applicable? Scand J Gastroenterol 2010;45:567-572.

24. Jung HK. Rome III criteria for functional gastrointestinal disorders: is there a need for a better definition? J Neurogastroenterol Motil 2011;17:211-212. 